\title{
Powder Injection Molding of Metal and Ceramic Parts
}

\author{
Joamín González-Gutiérrez, Gustavo Beulke Stringari and Igor Emri \\ Center for Experimental Mechanics, University of Ljubljana, Ljubljana, \\ Slovenia
}

\section{Introduction}

Powder injection molding (PIM) is a technology for manufacturing complex, precision, netshape components from either metal or ceramic powder. The potential of PIM lies in its ability to combine the design flexibility of plastic injection molding and the nearly unlimited choice of material offered by powder metallurgy, making it possible to combine multiple parts into a single one (Hausnerová, 2011). Furthermore, PIM overcomes the dimensional and productivity limits of isostatic pressing and slip casting, the defects and tolerance limitations of investment casting, the mechanical strength of die-cast parts, and the shape limitation of traditional powder compacts (Tandon, 2008).

Due to the demand of high performance materials and the miniaturization of complex components in various fields, PIM market has exceeded the \$1 billion mark in 2007, becoming approximately six times larger than 15 years before (German, 2008). This impressive growth rate is not expected to slow down in the next few years, as a recent report from Global Industry Analysts announced that together, world metal and ceramic PIM market is forecast to reach \$ 3.7 billion by the year 2017 (Global Industry Analysts [GIA], 2011). Metal powder injection molding (MIM) is still considered the largest segment of this market, accounting for more than $70 \%$ of global output. Although PIM is globally widespread, Europe and Asia-Pacific account for a major share of MIM segment, while USA is still the largest market for Ceramic Injection Molding (CIM) (GIA, 2011).

In Europe, the MIM production is dominated by automotive applications and the so called consumer market (which includes watches and eyeglasses), while the North American production is mainly applied to the medical/healthcare field. On the other hand, the Asian production, considered the largest one, is dominated by consumer electronics and information technology applications. The consumer electronics market is, indeed, one of the drivers behind MIM, whose growth is largely taking place in Asia, specifically in Taiwan, Malaysia, Thailand, China, Singapore and South Korea. Another growth factor is the expansion of medical component production also in Asia, as a larger population gains access to improved health care (German, 2008).

A recent increase in MIM sales has generated a need for new equipment, with a simultaneous investment in research and development. Typically, leader companies invest an average of $10.5 \%$ of sales in the combination of capital expansion and research. Besides 
this, several contract electronic assembly firms that used to purchase MIM components from custom molders have now elected to make from MIM a captive operation (German, 2008). This could lead to rapid growth for those operations since the relationship between design and production can be improved.

Stainless steel continues to dominate MIM applications, accounting for around half of the global production, reflecting the capture of components that would have otherwise gone to investment casting. Nevertheless, other materials as copper, nickel alloys, bronze and more recently tungsten alloys and titanium also represent important markets (German, 2008). On the other hand, the CIM market is mainly dominated by products made out of alumina, zirconia, and silicon or aluminium nitride powders (Ruprecht et al, 2002).

Typical components produced by PIM, either MIM or CIM, range from 0.002 to over $100 \mathrm{~g}$ (German, 2008). Furthermore, in both segments it is clear the progressive move towards smaller products, demanding improved technologies regarding machinery, process, and materials, hence leaving a still open field for applied research.

\section{Overview of process}

The PIM process presents countless variations which are used in the industry today. Invariably, it consists of four steps (Gonçalves, 2001; Tay et al, 2009):

- $\quad$ Feedstock preparation;

- Injection molding;

- Debinding;

- $\quad$ Sintering.

In Fig. 1 a flow chart illustrating the main stages of PIM is presented.

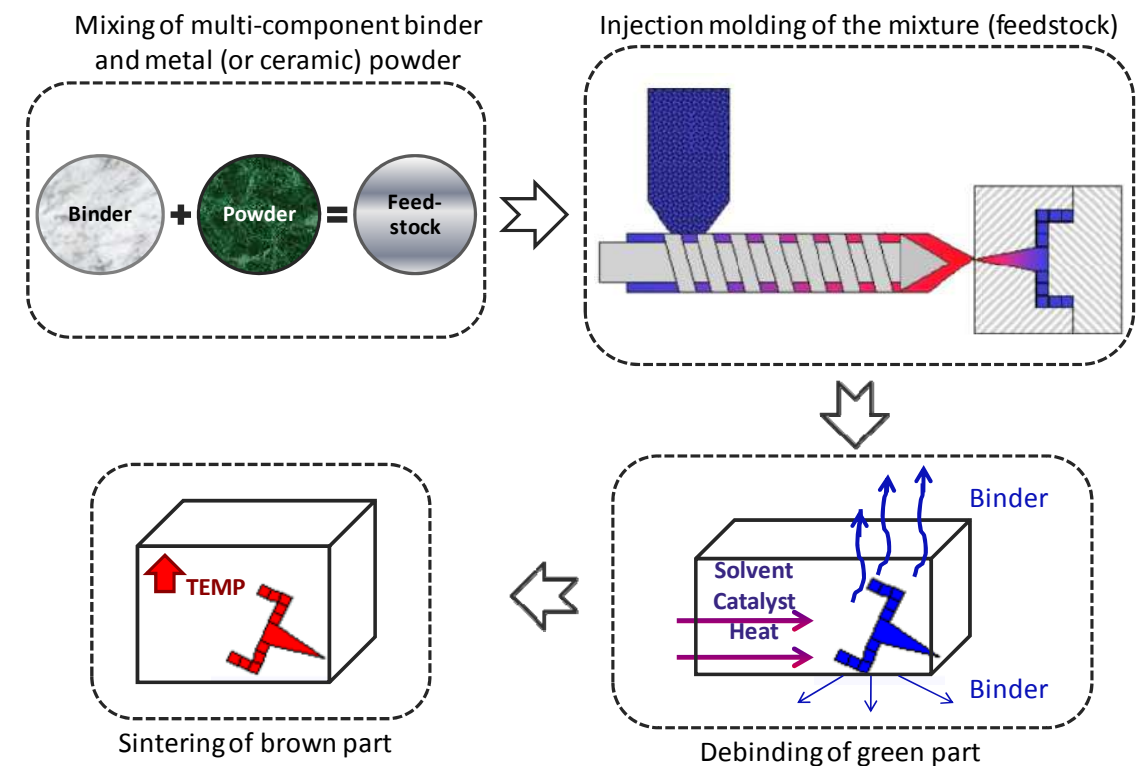

Fig. 1. Flow chart illustrating the main stages of PIM. 
The starting material for PIM, usually termed feedstock, is a homogeneous pelletized mixture of metal or ceramic powder and an organic multi-component binder. The binder and the powder are combined in a variety of compounding equipment, such as extruders and mixers. The mixture is then pelletized to an appropriate shape for feeding into the molding machine. The binder is simply a carrier medium for the powder and once a part is molded, the binder is removed in a subsequent step.

The injection molding process is mainly identical to conventional plastic injection molding. Nevertheless, some machine hardware changes are usually required to process a specific feedstock based on their compressibility and viscosity. Control of the molding process is vital for maintaining tight tolerances in subsequent steps. Most design advantages of PIM technology are captured during molding by relying on the flexibility of incorporating complexities in the tool. A molded part is called a "green part" and is oversized to allow shrinkage during sintering (Tandon, 2008).

Before sintering, it is necessary to remove the binder from the molded part. The debinding is the most expensive and time-consuming stage in the PIM technology. This removal process should be based on a progressive opening of the surface channels to facilitate the removal of vapors inside the nucleus (Gonçalves, 2001). Three main methods can be applied depending on the composition of the binder: thermal, solvent, and catalytic. In thermal debinding, the binder is removed by degradation, evaporation, or liquid extraction, at temperatures ranging from 60 to $600{ }^{\circ} \mathrm{C}$. The relatively long time associated with thermal debinding is greatly reduced using an organic solvent or in some cases even water to dissolve the soluble components of the binder, in the so called solvent debinding (Tandon, 2008). The catalytic debinding, in turn, focus in a solid-to-vapor catalytic degradation, as it is the case of exposing acetal-polyolefin-based feedstocks to acid vapors, resulting in much faster binder removal and superior handling strength when compared to thermal or solvent debinding (Krueger, 1996; Mathew \& Mastromatteo, 2003). Nevertheless, it is worth to point out that in all debinding methods, a skeleton of backbone binder often remains to impart adequate strength and shape retention up to the onset of sintering. This remaining backbone is thermally removed between $200{ }^{\circ} \mathrm{C}$ and 600 ${ }^{\circ} \mathrm{C}$ in a pre-sintering step (Tandon, 2008).

Sintering is the last stage of the process, providing the inter-particle bonding that generates the attractive properties from otherwise loose powder mass. Depending on the material, debound parts or "brown parts" are sintered at temperatures ranging from 1200 to $1600{ }^{\circ} \mathrm{C}$. It is essentially a removal of pores, accompanied by growth and strong adhesion among the adjacent particles, causing the retraction of the product whose dimensions usually reduce between 14 and 20\% (Gonçalves, 2001; Krug, 2002; Tandon, 2008). Therefore, green parts are oversized to compensate for the sintering shrinkage. The fine particle size used in the PIM process results in high sintered density ranging from $95 \%$ to $99.5 \%$ of theoretical, thus providing superior mechanical and corrosion properties as compared to press and sinter technology.

The following sections of this chapter have the goal to describe in more detail the different steps of the PIM and the desired characteristics of raw materials to be used during this process. 


\section{Feedstock preparation}

The first step in the powder injection process is the preparation of feedstock materials. The powder and binder are hot mixed above the softening point of the binder constituents to provide a uniform coating on the powder surface (Fig. 2A). The feedstock is prepared by compounding polymeric binders with fine metallic or ceramic powders. Commercially available feedstock material is generally supplied in the shape of pellets (Fig. 2B), so that is easy to handle before and during the injection molding step.

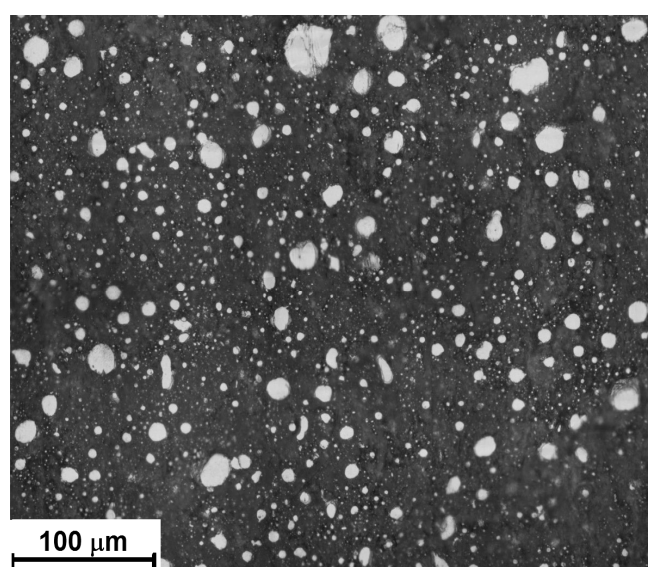

(A)

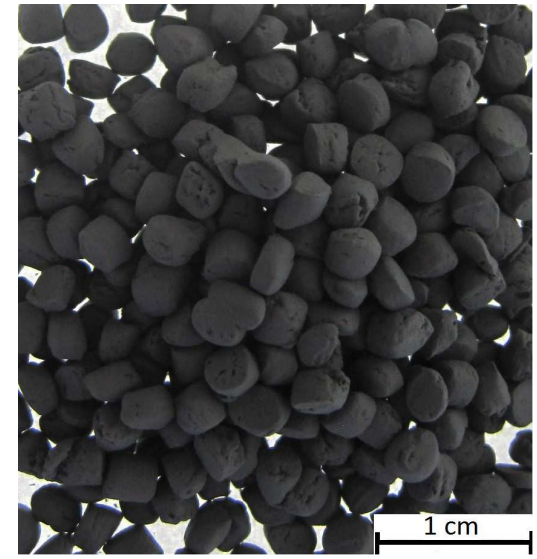

(B)

Fig. 2. (A) Micrograph of feedstock material showing metallic particles surrounded by polymeric binder, (B) Pellets of commercially available feedstock material Catamold ${ }^{\circledR}$ by BASF.

The powder content usually ranges from 50 to $65 \%$ in volume, although there are claims of optimized commercial formulations in which even more than $80 \%$ is used. If the powder content is found to be lower than $50 \mathrm{vol} \%$, the sintering ability of the feedstock and the final density of the part are significantly lowered. From another standpoint, it is also important to keep the viscosity of the feedstock as low as possible in order to facilitate the injection molding process, reason for why a powder content higher than 65 vol.\% should be handled with care (Merz et al, 2002).

One of the most important properties of the feedstock is certainly its homogeneity. A homogeneous distribution of powder particles and binder in feedstock is important as it helps to minimize segregation during the injection molding stage and later on to obtain isotropic shrinkage after debinding and sintering (Quinard et al, 2009). Avoiding segregation of feedstock components is necessary to prevent visual defects, excessive porosity, warpage and cracks in the sintered part (Thornagel, 2010).

The technique used for mixing binder and powder can influence the homogeneity of feedstock materials. Feedstock materials can be either produced in a batch process or continuously. Four different types of machines are generally used: high-shear mixers, roll mills, screw extruders and shear rolls. The first two are examples of batch operations while the last two are continuous. Which approach to take depends on the details of the 
application and the materials to be used to prepare the feedstock (Clemens, 2009). When using fine particles, which have a tendency to agglomerate batch mixing in planetary or zblade mixers (Fig. 3) is preferred, even though the process can take a couple of hours. In high volume productions, twin-screw extruders or shear rolls (Fig. 4) are employed for feedstock preparation (Hausnerová, 2011).
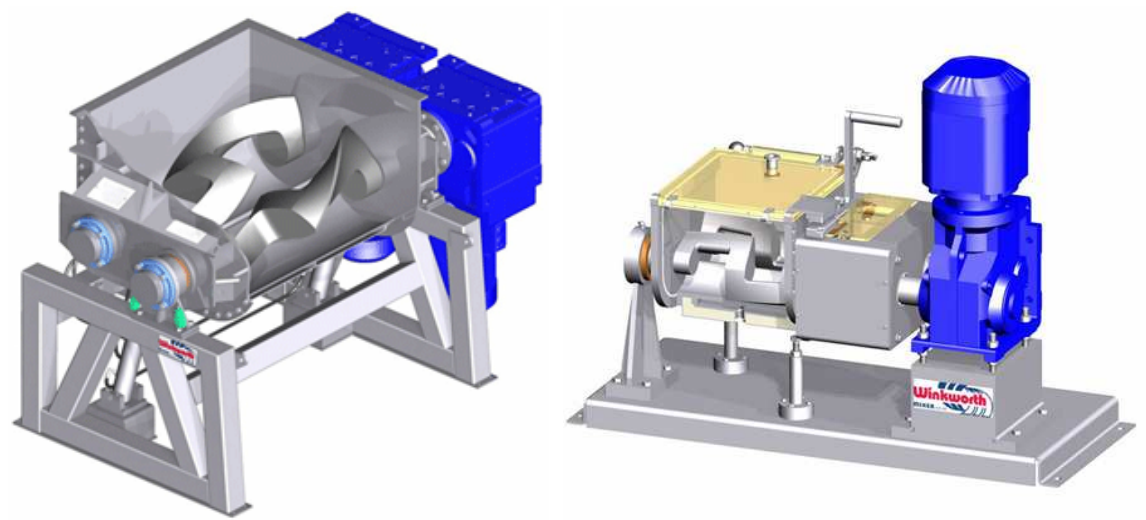

Fig. 3. Z-blade mixers for batch production of feedstock materials (courtesy of Winkworth Mixer Co., UK, www.mixer.co.uk).
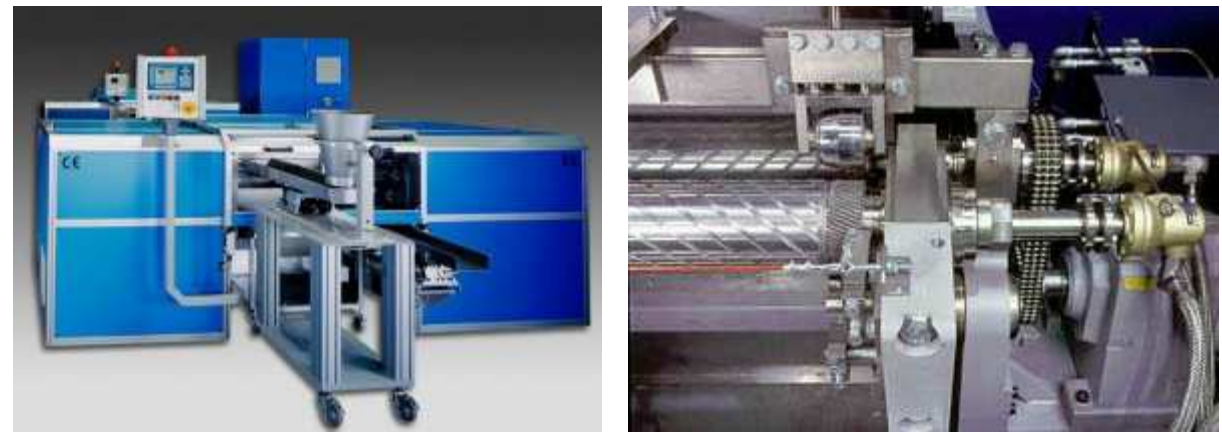

Fig. 4. Shear rolls for continuous production of feedstock materials (courtesy of Bellaform $\mathrm{GmbH}$, Germany, www.bellaform.com).

The following sections have the purpose to further describe the two main components of the feedstock material: binder and powder. The binder formulation, powder synthesis processes, and their desirable properties are indicated below.

\subsection{Binder formulation}

Binder vehicles used for PIM are usually designed as multi-component systems. One of the main components is termed backbone, which is a thermoplastic polymer that supports and maintains the shape of the molded part until the last stages of debinding (Thomas-Vielma et $a l, 2008)$. As examples of currently used backbones, it is possible to mention ethylene vinyl 
acetate (EVA), polyethylene (PE), polypropylene (PP), polystyrene (PS), polyethylene glycol (PEG), polymethyl methacrylate (PMMA) among others (Ahn et al, 2009; Chuankrerkkul et al, 2007; Krug et al, 2002; Thomas-Vielma et al 2008; Yang et al, 2002) (Fig. 5).

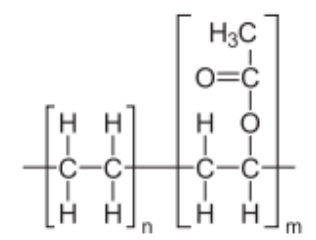

Ethylene Vinyl Acetate (EVA)

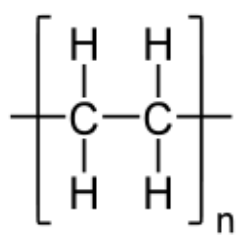

Polyethylene

(PE)<smiles>CC(C)CC(C)(C)C</smiles>

Polypropylene

(PP)

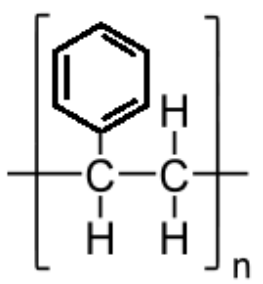

Polystyrene (PS)<smiles>COCCCO</smiles>

Polyethylene Glycol (PEG)<smiles>COC(=O)C(C)(CC(C)(C)C)C(C)(C)C</smiles>

Polymethyl Methacrylate (PMMA)<smiles>CC(C)OC(C)C</smiles>

Polyoxymethylene (POM)

Fig. 5. Examples of polymers used in different binder formulations.

The second component, usually in a proportion similar to the backbone is commonly a wax, as paraffin or carnauba wax, or in some cases even agarose, that improves the material flowability (Ahn et al, 2009). Besides improving flowability, such component should be easily removed in early stages of debinding, in general via solvent methods, leaving open pores that will allow the gaseous products of the remaining polymer to diffuse out of the structure (Thomas-Vielma et al, 2008). Even though this low-melting temperature component has an important role in the process, it is worth to mention that the mechanical integrity of the final product is reduced as its proportion increase after certain limits (Tseng \& Hsu, 1999).

The importance of each of these two main binder components can be better understood with a further description of the debinding mechanism. It is worth to remember that at the beginning of debinding no pores or free space are shown in the molded part, hence the backbone component has a crucial role retaining the shape of the part, and avoiding cracks while the low-melting component leaves this molded structure (Thomas-Vielma et al, 2008). In the last stages of debinding, it is due to the open porous created by this second component that the backbone can diffuse out without damaging the structure of the product. If not by these pores, an excessive pressure would easily build up within moldings from the degradation species during burnout, causing distortions and cracks (Tseng \& Hsu, 1999).

However, the emergence of a POM-based binder system for PIM has made it possible to remove the polymer vehicle from up to $35 \mathrm{~mm}$ thick sections without the use of any wax or 
low molecular weight component (Krug et al, 2000). As previously described, POM (Fig.5) decomposes predominantly to formaldehyde in the presence of an acid vapor (as oxalic or nitric acid) well below its softening point, that is, in the solid state, avoiding the cracks and bloating that can be caused by the boiling of the binder (Krug et al, 2001). It is also important to mention that the polymer is not penetrated by the gaseous acid and the decomposition proceeds exclusively at the gas-binder interface with a nearly planar debinding front moving through the compact. In this sense, gas exchange is limited to the already porous shell and the buildup of an internal pressure is avoided. Nevertheless, POM-based binder systems often contains up to $30 \%$ of polyethylene which does not react with acid vapors, acting as a backbone until being burned out during the sintering cycle.

Finally, additives as surfactants can compose the binder, being stearic acid the most common example of them. These surface-active dispersants normally present a low melting temperature and affinity to preferentially adsorb onto powder surfaces, forming a densely thin outer layer on a particle surface which leads to a more homogeneous packing structure (Chan \& Lin, 1995). However, bubbles and cracks were reported to occur as the amount of the surfactants increases, presumably owning to the reduced vaporization temperature since the surfactants are composed of mostly short molecules (Tseng \& Hsu, 1999).

\subsection{Powder manufacturing}

It is from the powder material that the final product will be constituted, and its selection often involves the combination of a tailored particle size distribution to maximize packing densities. Powders for ceramics and metals can be obtained from a variety of methods; the following section will describe some of the methods used for obtaining ceramic and metallic powders of various shapes and sizes.

\subsubsection{Ceramics}

The methods used for synthesis of ceramic powders range from mechanical methods that involve grinding or milling (commination) for size reduction of a coarse, granular material to chemical processes involving chemical reactions under carefully controlled conditions. Generally speaking, mechanical methods are considerably cheaper than chemical methods. However, chemical methods offer better control of the powder characteristics, such as shape and size (Rahaman, 2003).

Mechanical methods are generally used to prepare powders from naturally occurring raw materials. Operations such as crushing, grinding and milling are classified as mechanical methods. Machines like jaw, gyratory and cone crushers are used to produce powders in the size range from 0.1 to $1 \mathrm{~mm}$. In order to achieve particles with less than $1 \mathrm{~mm}$ milling is generally used. Mills used today include high-compression roller mills, jet mills and ball mills (Rahaman, 2003).

Chemical methods are generally used in the synthesis of powders of advanced ceramics from synthetic materials or from naturally occurring materials with a significant chemical refinement. The most common chemical methods are summarized in Table 1. It is important to mention that many chemical methods require a milling step to break down agglomerates and for determining the average particle size and particle size distribution (Rahaman, 2003). 


\begin{tabular}{|c|c|c|}
\hline Method & Advantages & Disadvantages \\
\hline $\begin{array}{c}\text { Solid-state reactions: } \\
\text { - Decomposition } \\
\text { - Reactions between solids }\end{array}$ & $\begin{array}{l}\text { Inexpensive, simple } \\
\text { equipment used }\end{array}$ & $\begin{array}{l}\text { Agglomerated powders, } \\
\text { limited homogeneity for } \\
\text { multicomponent powders }\end{array}$ \\
\hline $\begin{array}{c}\text { Liquid solutions: } \\
\text {-Precipitation } \\
\text {-Solvent vaporization } \\
\text {-Gel routes }\end{array}$ & $\begin{array}{l}\text { Small particles, chemical } \\
\text { homogeneity, high purity, } \\
\text { composition control }\end{array}$ & $\begin{array}{l}\text { Agglomerated powders, poor } \\
\text { for non-oxides, expensive }\end{array}$ \\
\hline Non-aqueous liquid reaction & Small particles, high purity & Limited to non-oxides \\
\hline Gas-solid reactions & $\begin{array}{c}\text { Inexpensive for large particle } \\
\text { sizes }\end{array}$ & $\begin{array}{l}\text { Low purity, expensive for fine } \\
\text { powders }\end{array}$ \\
\hline Gas-liquid reactions & Small particles, high purity & $\begin{array}{l}\text { Expensive, limited } \\
\text { applicability }\end{array}$ \\
\hline Reaction between gasses & $\begin{array}{l}\text { Small particles, high purity, } \\
\text { inexpensive for oxides }\end{array}$ & $\begin{array}{l}\text { Agglomerated powders, } \\
\text { expensive for non-oxides }\end{array}$ \\
\hline
\end{tabular}

Table 1. Commonly used chemical methods for manufacturing of ceramic powders (Rahaman, 2003).

\subsubsection{Metals}

Most metal powders can be produced by comminution of the refined ore. Milling and grinding are methods to produce powders of any degree of fineness from friable or malleable metals (e.g. titanium or steel). However not all particle sizes are sinterable, in general particles have to be below $45 \mu \mathrm{m}$. Currently, there is a tendency to use submicron and nanoparticles, since a better packing density can be achieved, their activation energy is higher and their sintering temperature is lower (Shearwood et al, 2005). Nevertheless, care must be taken when handling nano powders since they can be explosive or can easily oxidize; therefore most of the time powder metallurgy utilizes particles in the 1 to $45 \mu \mathrm{m}$ range (Hartwig et al, 1998). In particular, for metal injection molding the mean particle size ranges from 5 to $15 \mu \mathrm{m}$ (Krug et al, 2002). This type of size particles can generally be achieved in ball mills, rotary mills, planetary mills, jet mills, vibrating grinders, stampers and crushers (Schrader et al, 2000).

Nickel or iron can react with carbon monoxide to form metal carbonyls; carbonyl vapors undergo decomposition by instantaneous mixing with a large volume of hot inert gas followed by quenching the aerosol formed by diluting and cooling. Metal powders from carbonyls have high purity, small and uniform grain size, and particles that are dense and round (Neikov et al, 2009; Schrader et al, 2000). The most commonly used powders in today's MIM production are carbonyl powders. Simple mixtures of iron and nickel carbonyl powders are the basis of powder mixtures for metal injection molding; other metals included in these mixtures include heat treatable steels and stainless steels (Hartwig et al, 1998).

Metals or alloys that may be homogeneously melted can also be atomized in a stream or air or an inert gas (often argon). Some metals are melted first and later injected through an orifice into the stream to later be dropped in water, such process is called shotting. Other metals like iron and stainless steel may be fused in an electric arc and refractory metals in a plasma arc. For example, titanium droplets freeze to powder after being thrown from the end of a rapidly rotating bar heated by a plasma arc in a helium atmosphere (Schrader et al, 
2000). Water atomization leads to irregular particles with a good yield of particles below 45 $\mu \mathrm{m}$. Gas atomized powders leads to mostly spherical particles (Fig. 6) but the yield of particles below $45 \mathrm{~mm}$ is limited (Hartwig et al, 1998).

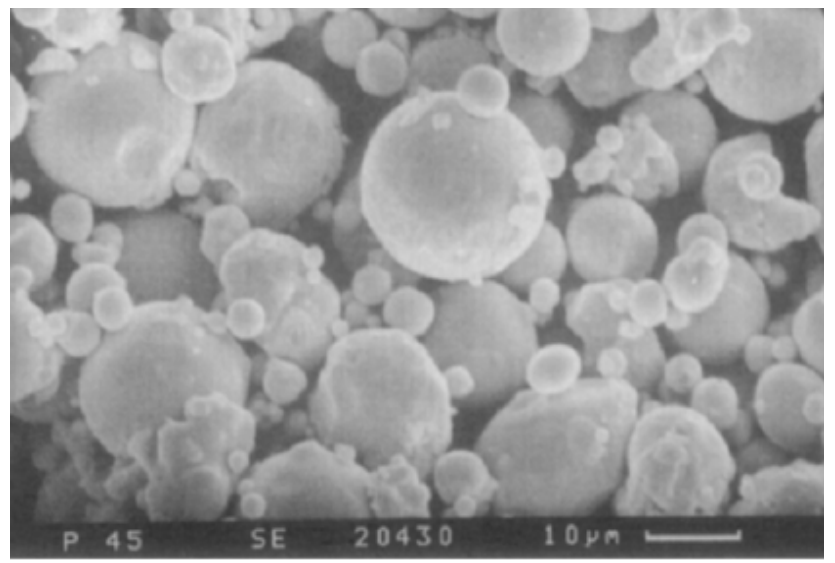

Fig. 6. SEM micrograph of gas atomized stainless steel powder (Hartwig et al, 1998).

Metal powder can also be electrolytically deposited under the right conditions. The deposited material may have to be broken up and ground to achieve the desired fineness, heated to be annealed, drive off hydrogen, sorted and blended. Electrodeposited powders are among the purest powders available, but they are pricier (Schrader et al, 2000).

Other less common methods of manufacturing metallic powders include vapor condensation, chemical decomposition, ordinary machining, impacting of chips and scrap, and granulation by stirring vigorously during solidification (Schrader et al, 2000). The most common methods applied for obtaining powders of different metals can be found in Table 2 .

\begin{tabular}{cc}
\hline Production method & Used for \\
\hline Chemical & Tantalum, tungsten \\
\hline Electro-chemical & Copper, iron, nickel \\
Thermo-chemical & Carbonyl-iron, nickel \\
Mechanical (comminution \& atomization) & Steels, titanium, intermetallics \\
\hline
\end{tabular}

Table 2. Common production methods for metal injection molding powders (Hartwig et al, 1998).

\subsubsection{Submicron powders}

With the growing demand for microparts (Fig.7) to be used in consumer electronics, automotive parts and in the biomedical field, there is also a requirement to use powders with smaller particles and perform what is called micro-PIM. It is generally accepted that the smallest feature of a part can only be ten times larger than the mean particle diameter, thus in order to obtain microparts with good edge definition and shape retention, submicron or nanoparticles need to be used. Also, submicron powders have an enhanced sintering activity, which is beneficial for attainment of high-density bodies at lower sintering 
temperatures. Such powders are still under development since there are many issues that need to be resolved.
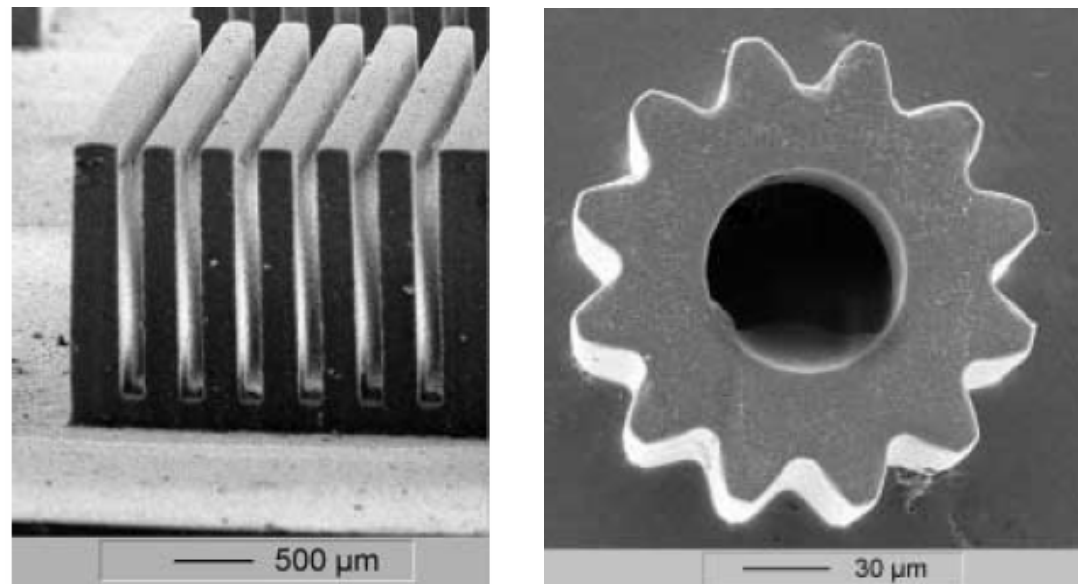

Fig. 7. Ceramic microparts produced by PIM (Pioter et al, 2001).

Submicron powders tend to be pyrophoric and therefore it is essential to avoid any oxidation during handling. One way to avoid oxidation is to handle submicron powders in a glove box under argon; inside this box powders are coated with a binder constituent, in order to avoid oxidation in the subsequent processing steps of feedstock compounding and injection molding (Zauner, 2006). Another issue that arises as the particle size decreases below $1 \mu \mathrm{m}$ is the greater tendency for particle-particle interaction, which results in agglomerates. If many agglomerates are present, the final sintered part could have a non-uniform distribution of particles and little benefit is achieved compared to coarse particles. Therefore, the use of submicron powders requires special handling and mixing procedures in order to minimize detrimental effects due to the presence of agglomerates (Rahaman, 2003).

\subsection{Desired properties of feedstock}

A homogeneous distribution of powder particles and binder in feedstock is important as it helps to minimize segregation during the injection molding stage and later on to obtain isotropic shrinkage after debinding and sintering (Quinard et al, 2009). Avoiding segregation of feedstock components is necessary to prevent visual defects, excessive porosity, warpage and cracks in the sintered part (Thornagel, 2010). The technique used for mixing binder and powder can influence the homogeneity of feedstock materials. As shown by Quinard et al (2009), using a twin-screw extruder yielded a better binder distribution. However, when using a z-blade mixer a better binder volume distribution around the powder particles was achieved, that would lead to an isotropic shrinkage after sintering.

Understanding which the desired properties are for a binder is a crucial step in the optimization of PIM regarding both productivity and quality of the final product. Only a few authors have been working in this direction and not all of them agree in their 
conclusions. For example, regarding the flow characteristics, German (1990) highlighted the importance of low viscosity at the molding temperature, a characteristic stressed by Liu et al (2001) as even more important in the case of micro moldings. Ahn et al (2008) mentioned that a high drop in viscosity at the high shear rates (shear-thinning behavior) is also a desired property for cavity filling with less energy, especially for complicated geometries. However, stability of the mixture should be taken into account in order to avoid powderbinder separation.

The binder should also be strong and rigid after cooling and present small molecules to fit between particles (German, 1990). No agreement is found regarding the viscositytemperature dependence, which is suggested to be the least as possible by German (1990) but high by Thomas-Vielma et al (2007). Nevertheless, Ahn et al (2009) shown that contrary to the viscosity-shear rate dependence, the viscosity-temperature dependence is more influenced by the powder selection than the selection of the binder itself.

High thermal conductivity, low thermal expansion coefficient, short chain length, no orientation, low contact angle and good adhesion with powder, capillary attraction of particles and be chemically passive with respect to the powder are also desired properties that should be taken into account when selecting binder components (German, 1990).

Thomas-Vielma et al (2007) reported that defects as cracking (Fig. 8), slumping and sagging are partly related to the swelling of the binder component during solvent debinding, a problem that can be reduced by increasing the crystallinity of the polymer acting as a backbone. Besides this, the decomposition of such polymer should be non-corrosive, nontoxic, and having low ash content (German, 1990).

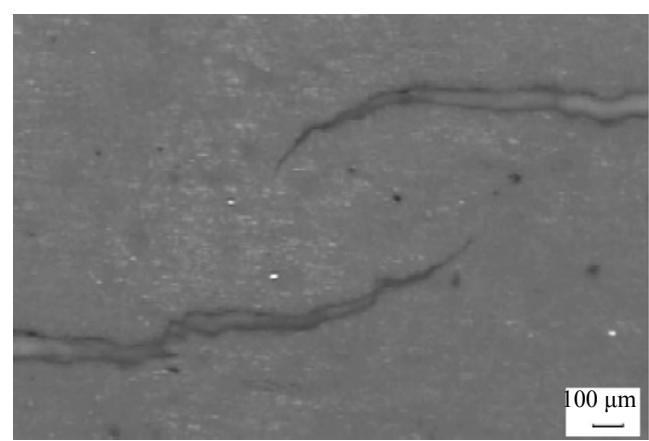

(A)

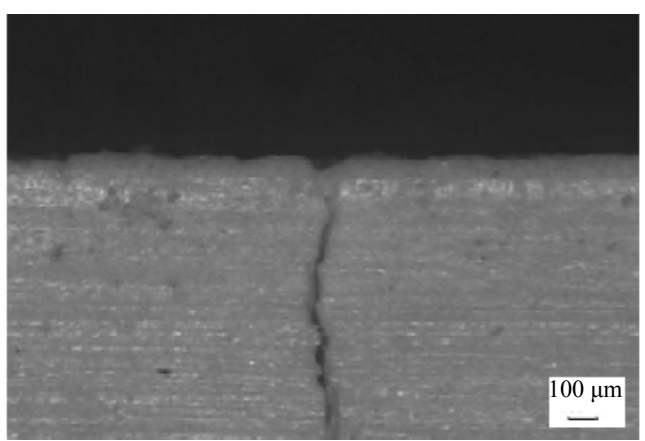

(B)

Fig. 8. Appearance of (A) cracks and (B) transverse cracks after thermal debinding on alumina parts (Thomas-Vielma et al ,2007).

As can be observed in this section, the thermal and time-dependent properties of the different components of the binder play an important role in the quality of the final product. Furthermore, it also influences the choice of process parameters, as injection pressure and heating ramp, determining the cost and the productivity of the process. In this sense, understanding and improving the properties of this multi-component system or its single components have a great importance to the optimization of the PIM technology. 


\subsection{Possible feedstock optimization}

Rheological and time-dependant properties represent powerful tools for optimizing the PIM process. The binder's rheological properties (flowability) are important to determine the optimal binder formulation or selecting a proper additive. It has been suggested in the literature that the viscosity of the binder should be less than $0.1 \mathrm{~Pa} \cdot \mathrm{s}$ in order to provide the PIM feedstock with a viscosity below $1000 \mathrm{~Pa} \cdot \mathrm{s}$ (German, 1990). Having low viscosity allows for easy molding. However, it is generally known that low viscosity materials have also low mechanical properties when solidified. Having low mechanical properties transforms into a "green part" which is prone to deformation and breakage if not handle with care, especially right after molding when the binder is still soft. For this reason a compromise has to be made between the molten rheological properties and the solid mechanical properties of binder.

Bimodality in the molecular mass distribution (Fig. 9) of binders is still an issue that has not been extensively studied. Nevertheless, recent investigations have shown its potential to bring two main benefits to the process of PIM: lower the viscosity of the feedstock in the molten state and maintaining the mechanical strength of the green part, all of this without modifying the chemistry of the binder.

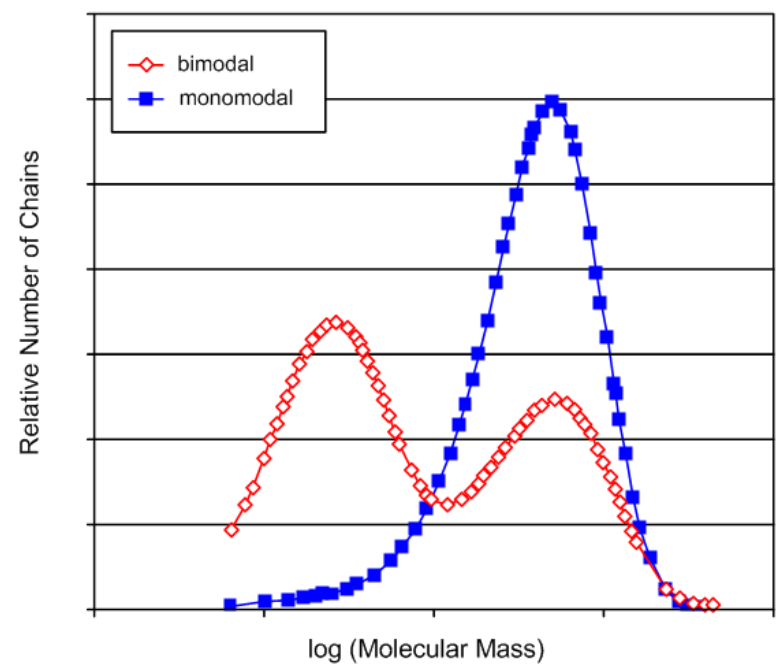

Fig. 9. Schematic representation of bimodal and monomodal molecular mass distribution in polymeric materials.

It has been observed that bimodality in the molecular mass distribution improves the shear relaxation modulus (Emri \& von Bernstorff, 2006) and the shear creep compliance (Kubyshkina et al, 2011) of polyamide 6 in the solid state. Based on those results, Stringari et al (2011) studied the effect of bimodal molecular mass distribution in POM and it was shown that bimodality decreases viscosity without significantly affecting the mechanical properties (shear creep compliance) of the potential PIM binder. The mechanisms for such behavior could be explained as follows: The addition of small polymer chains through bimodality increases the flowability of the binder in the molten state, since such small 
molecules can act as internal lubricants for the larger molecules facilitating their movement. However, when in the solid state the smaller molecules could fit between the larger ones, creating a closely packed structure that cannot be deformed as easily, translating into improved mechanical properties.

Once good flowability of the binder has been obtained it is important to check the flowability of the feedstock material. The flowability of feedstock will not only depend on the viscosity of binder but also on the powder loading. The optimal powder loading refers to a concentration of powder for which a compound exhibits good flow properties, good dispersion and distribution, and flow stability in the shear rates applied during injection molding $\left(10^{2}-10^{5} \mathrm{~s}^{-1}\right)$. Rheological data represents an extremely useful tool to evaluate optimum powder loading. The ratio of feedstock's viscosity to binder's viscosity known as the relative viscosity is an important parameter used to determine the maximum packing fraction for a particular powder-binder compound. As the powder concentration reaches the maximum level the flow of feedstock material is restrained and a sharp increase in relative viscosity is observed (Hausnerová, 2011).

The maximum loading level in a feedstock material is dependent on the characteristics of the powders and how these particles are packed. The packing behavior of particulate materials depends largely on their particle size, shape and surface characteristics. Packing behavior has been explained by model systems with closely defined size and shape distributions. Even though real materials do not have a well-defined shape and size distribution, the principles derived from models appear to work reasonably well. Theoretical maximum packing has been studied for spherical, smooth, regular, mono-sized particles, which can readily move past another. With these particles a maximum ordered packing fraction of 0.74 has been established from geometrical principles. In order to increase the packing fraction of powders, small particles to fill in the pores in the packed structure obtained from larger particles are used and then use even smaller particles to fill in the remaining pores and so on. This approach is known as multimodal packing and much effort has been devoted to find the optimal particle size ratios that yield maximum packing fractions in the field of particulate composites (Rothon, 2003). German (1990) has already pointed out that an ideal PIM powder should combine large and small particles in a tailored size distribution. Hausnerová et al (1999) showed that feedstock material containing particles with a monomodal particle size distribution exhibit higher viscosity compared to feedstock with bimodal powder. The current explanation for this behavior is that the smaller particles fill the inter-particle voids created by large particles, thereby releasing previously immobilized molten binder (Hausnerová, 2011).

\section{Injection molding}

The second step in the PIM process is molding the feedstock into the desired shape. The most popular method is to use a reciprocating screw, horizontal, hydraulic or electric machine in which a screw stirs the feedstock inside the barrel while it is melting. After melting the feedstock the screw acts as a plunger to generate the pressure to fill the die (Stevenson, 2009). Conventional screw-type injection molding machines consist of a clamping unit, injection unit and control system. The clamping unit houses the mold which is generally comprised of two halves. When the clamping unit is closed, material can be injected into the mold, when the clamping unit is open the molded part can be removed. 
The injection unit consists of a screw, a heating system and a nozzle. The screw transports the material inside a barrel, compresses it and removes any bubbles. The heating system brings the material to an appropriate temperature for easy flow. The nozzle is the conduct through which the heated feedstock is injected into the mold under pressure. The control system of a modern injection molding machine includes hardware and software where the processing conditions are set and saved to ensure the reproducibility of previously employed production cycles (Arburg, 2009).

Molding of the feedstock is comparable to the injection molding of plain thermoplastics and it has the following stages (Arburg, 2009; German \& Bose, 1997):

a. The pelletized feedstock is placed in the hopper of the injection molding machine.

b. The binder in the feedstock is melted by the heating system.

c. The molten material is injected under high pressure (60 $\mathrm{MPa}$ or even more) into the mold cavity which is mounted in the clamping unit. The feedstock must have low enough viscosity that it can flow into the die cavity under pressure.

d. The mold remains closed while cooling channels in the die extract heat from the molten feedstock and solidify the polymer to preserve the molded shape.

e. After solidification of the binder, the nozzle of the injection die is pulled away from the mold by moving the injection unit. The clamping unit opens and the molded part is ejected by the ejector system of the machine.

f. The green part is removed from the mold. Due to the fragile nature of most green parts, the removal process is done by hand or by a robotic system in order to prevent shocks or impacts which could deform or even break the molded part.

The shaping equipment used in PIM is the same as the one used for plastic injection molding. Due to the size of molded parts, injection molding machines used for PIM are in the lower range, with clamp force typically less than 100 tons, 18 to $25 \mathrm{~mm}$ screws and shot size of less than $30 \mathrm{~cm}^{3}$ (Stevenson, 2009). However, the main important difference when dealing with injection molding of any powdered part is that many of the components of the molding machine are subject to a more intense wear, particularly screws, non-return valves, cylinders and molds (Rosato \& Rosato, 1995).

Injection molding machines for processing of powdery materials are optimized with wearresistant components, through special hardening processes or utilization of alloys. For example, when dealing with stainless steel feedstock materials, hardening with carbon nitride is recommended by feedstock manufacturers. And when working with ceramic and hard metals, boride cladding or carbide hard facing are recommended. Since harder screws are more brittle, lower torque limits during startup are used to prevent screw breakage in PIM. The solid feedstock pellets cause the most abrasive wear in the feed section of the screw, thus the feedstock should be melted as early as possible in the injection cycle (Stevenson, 2009).

Screw geometry of PIM machine is adopted to lower the compression rate and extend the compression zone as compared to screws used for thermoplastics (Hausnerová, 2011). Compression ratios used in PIM tend to be in the lower range. Ratios between 1.2 and 1.8 are considered acceptable and a ratio of 1.6 is considered to be optimal for the removal of air between granules. It is also important to mention that when calculating the barrel capacity of the injection unit, the barrel rating must be scaled up to take into account the higher density of the PIM feedstock (Stevenson, 2009). 
The injection molding step can create undesirable features such as gate and ejection pin marks, which must be located in non-critical locations otherwise they must be removed after fabrication. Other design limitations include gradual thickness changes, minimized wall thickness, round corners to reduce stress concentrations and risk of crack appearance, and minimum undercuts on internal bores. Whenever possible, it is important to design PIM parts with one flat surface, which allows the use of standard trays during sintering, otherwise special trays are required (Hausnerová, 2011).

\section{Debinding}

Before sintering, the organic binder must be removed without disrupting the molded powder particles; this process is commonly referred as debinding. Organic polymers have to be removed completely from the "green part", since carbon residues can influence the sintering process and affect the quality of the final product negatively. Moreover, binder removal is one of the most critical steps in the PIM process since defects can be produced by inadequate debinding, like bloating, blistering, surface cracking and large internal voids. It has been shown that the rate of binder removal plays a main role in the defect production due to structural changes in capillaries inside the green part (Oliveira et al, 2005).

The most commonly used debinding techniques include: thermal, solvent and catalytic. However there also exist some experimental techniques such as plasma debiding (dos Santos et al, 2004). The following sections have the aim to provide the reader with a description of the different debinding techniques showing their benefits and limitations.

\subsection{Thermal debinding}

Thermal debinding utilizes the mechanisms of thermal degradation of organic binders, which is based on the successive dissociation of polymers to produce light molecules that are later evaporated out of the surface of the molded part. Since the thermal degradation process is different for different polymers then thermal debinding time is greatly influenced by the type of polymer used. The binders developed in the original PIM process were a mixture of polyethylene or polypropylene, a synthetic or natural wax and stearic acid. Feedstock materials based on such binders can be removed thermally. However, it has been shown in the literature that POM and polybutyl-methacrylate (PBMA) have a much faster degradation than other polymers such as polypropylene (PP) and ethylene-vinyl-acetate (EVA) (Kankawa, 1997). It should also be noted that the choice of atmosphere under which thermal debinding is performed influences the rate of binder removal and some characteristics of the final piece such as density, carbon or oxygen content (Quinard et al, 2009).

In general, it can be said that thermal debinding is an inefficient process that can result in a poor etching of the piece surface if not properly controlled. Additionally, increasing the temperature too fast may produce an excessive increase of vapor pressure in the core of the molded piece leading to defects. Consequently, in order to reduce the risk of cracks or shape deformation, low heating rates are generally used, resulting in a long debinding time, ranging from 10 to $60 \mathrm{~h}$ (dos Santos et al, 2004). However, thermal debinding is still selected due to its simplicity, safety and respect for the environment as compared to solvent and catalytic binder removal (Quinard et al, 2009). 
In order to increase the efficiency of the thermal debinding process a vacuum pump is used to continuously pull binder vapor away from the heated parts. Initially, the heating rate is typically $0.5^{\circ} \mathrm{C} / \mathrm{min}$ or less until a temperature of $100{ }^{\circ} \mathrm{C}$ is reached; this temperature is hold for approximately $4 \mathrm{~h}$ and later it is increased to $400{ }^{\circ} \mathrm{C}$ using a heating rate close to 1 ${ }^{\circ} \mathrm{C} / \mathrm{min}$, this temperature is maintained for $2 \mathrm{~h}$. During the entire process the pieces are constantly exposed to a gas flow, in order to remove the binder vapors, which are condensed and collected in a trap. Finally when all the binder is removed the temperature is increased and the sintering process can begin. This is one of the main advantages of vacuum debinding. However, the debinding process is still around 10 hours long, since the main mechanisms of debinding is still thermal degradation (dos Santos et al, 2004).

Another variant of the thermal debinding process includes the use of a wicking material (porous substrate) which is in contact with the "green part" or compact. In industrial practice the compact is buried in the wicking material and therefore the binder is removed from the compact in all directions (Somasundram et al, 2008). A simplified model is shown in Fig. 10. The porous substrate provides a medium for capillary flow as the binder viscosity decreases due to the increase of temperature. Wicking thermal debinding is performed at temperatures where the binder melts, therefore the binder can flow out of the component into the pores of the contacting substrate. Wicking involves liquid extraction; while other thermal process requires the binder to be in gaseous state and thus the temperatures are generally lower but the process is slower due to the slower transport of liquid compared to a gas (German \& Bose, 1997).

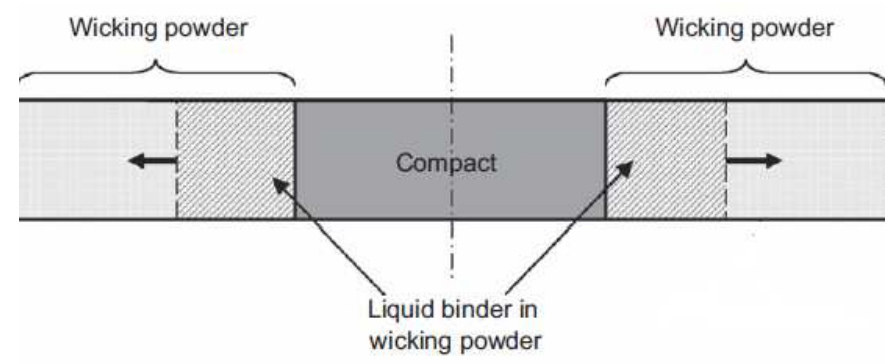

Fig. 10. Schematic cross-section of compact (green part) surrounded by wicking powder during thermal debinding (adapted from Somasundram et al, 2008).

\subsection{Solvent debinding}

Solvent debinding is done by immersing the molded part in a gaseous (Fig. 11) or liquid solvent such as ethanol, hexane, heptanes and acetone, at low temperature, typically 50 to 60 ${ }^{\circ} \mathrm{C}$ (Torralba et al, 2011). The solvent removes at least one of the binder components and produces an open porosity. The next step in solvent debinding is binder burnout to remove the backbone of the binder that provides adequate shape retention up to the onset of sintering (dos Santos et al, 2004; Aggarwal et al, 2007). Binder backbone removal is generally done thermally between 200 and $600{ }^{\circ} \mathrm{C}$ in a pre-sintering step (Tandon, 2008).

The effectiveness of solvent debinding is strongly related to the geometry of the "green part" in particular to the surface to volume ratio, since the solvent needs to penetrate the part. Other factors that influence solvent debinding include temperature and porosity 


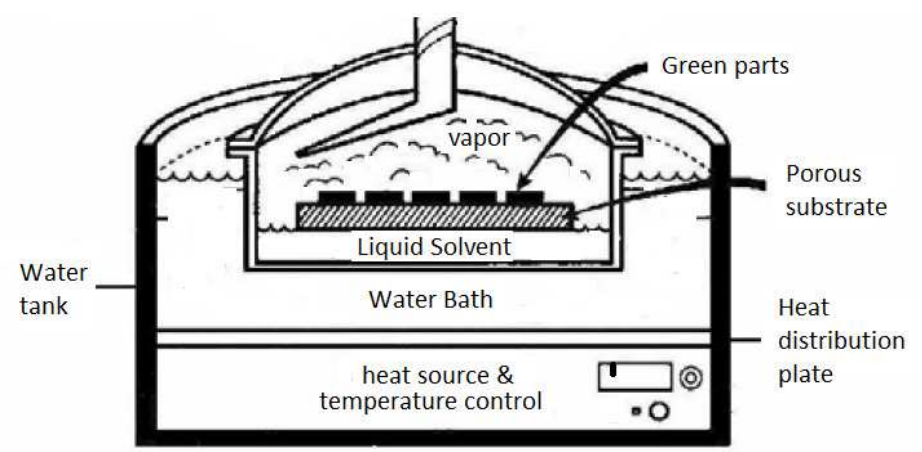

Fig. 11. Solvent vapor debing process (adapted from German \& Bose, 1997).

evolution. The temperature effect is related to an increase in interaction between soluble binders and solvents as temperature increases, in other words temperature changes the solubility and diffusion coefficient of the binder (Oliveira et al, 2005).

There is a tendency to try to use binders that are soluble in water, since handling the aqueous solvent is much easier than handling organic solvents. Good examples of watersoluble binders include polyethylene glycols, polyethylene oxide, polyvinyl alcohols, starches and polyacrylamide. All of these polymers have monomers containing oxygen and nitrogen that are hydrophilic. The time to debind is a function of the powder material, particle size, part geometry, water temperature, water circulation and water volume relative to mass of the "green part". All of these variables are interrelated with each other and must be optimized for a particular piece. After debinding, parts are usually dried in a forced air furnace at 65 to $75^{\circ} \mathrm{C}$ for at least three hours. The drying step can be included as part of the sintering program. Water can be regenerated after debinding by distillation and therefore a closed process water circuit can be used (Auzene \& Roberjot, 2011).

Another type of solvent debinding is the use of a supercritical process. When applying supercritical extraction, the operative pressures of solvents such as carbon dioxide or propane are kept around $10 \mathrm{MPa}$ and temperatures are less than $100{ }^{\circ} \mathrm{C}$. The use of low temperatures results in slow diffusion of the binder to the surface of the green part, resulting in long processing times. Super critical debinding is not widely employed in commercial operations due to the long processing times and elevated cost of the necessary equipment, which require high precision control in temperature and pressure (dos Santos et al, 2004).

\subsection{Catalytic debinding}

Catalytic debinding can be used for binders that decompose into smaller molecules in the presence of a catalyst when exposed to the appropriate temperature. The most common example is a binder based on POM sometimes also referred as polyacetal. A commercial example of a feedstock with a POM based binder is Catamold ${ }^{\circledR}$ produced by BASF. By using a catalyst, the polymer at the surface of the "green part" is cracked into monomers and evaporates. As the monomers evaporate, pores are created that expose the polymer beneath the surface and the depolymerization process continues deeper into the molded part. Thus the debinding occurs from the outside inwards. Shorter debinding times are achieved with the use 
of the catalytic process, since the rate of diffusion of monomers is high due to the small size of their molecules (Clemens, 2009). Furthermore, the small molecules generated have a high vapor pressure, which greatly minimizes the potential for capillary condensation and allows thick part sections to be debound (Krueger, 1996).

Polyacetal-based binders depolymerizes catalytically under acidic conditions yielding formaldehyde, a direct solid to gas transition (Fig. 12). Temperature and catalyst concentration play a key role in determining the rate of debinding, as well as the particle size of the powder and geometry of the molded part. This type of debinding is performed below the melting temperature of $\mathrm{POM}$, generally between 110 and $150{ }^{\circ} \mathrm{C}$. The use of these relative low temperatures prevents the formation of a liquid phase and thus prevents deformation of the "green part" due to gravitational distortion or stress relaxation (Fu et al, 2005). Also the internal gas pressure is low, which minimizes the danger of crack formation and propagation. For POM, $100 \%$ nitric acid $\left(\mathrm{HNO}_{3}\right)$ is the most suitable catalyst. Even though nitric acid is a strongly oxidizing agent, its anhydrous form does not react with most of the commonly used metal powders (Krueger et al, 1993).

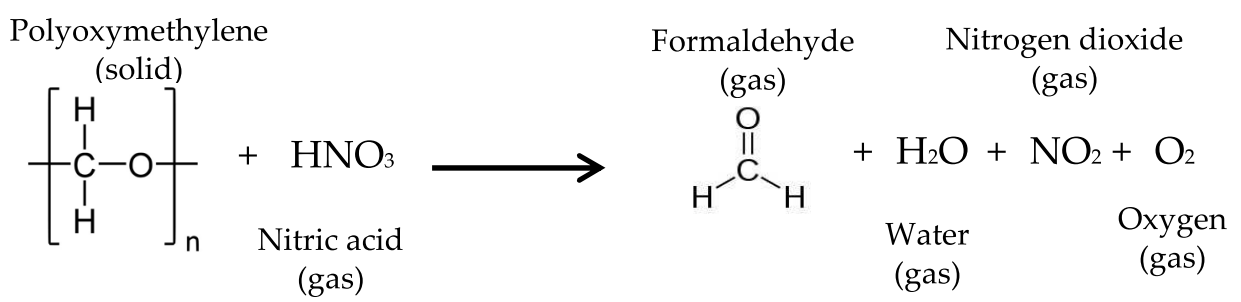

Fig. 12. Decomposition of POM in the presence of nitric acid.

The debinding time depends on the quantity of catalysts and temperature used. An increase of these two factors can shorten the time of depolymerization. However, there are some limitations as to how much temperature and catalyst content can be increased, not only due to possible damage to the molded part but also due to health concerns. As previously mentioned, POM decomposes into formaldehyde, which due to its toxicity has limitations in the allowable quantity $(0.1 \mathrm{~kg} / \mathrm{h})$ and concentration $\left(20 \mathrm{mg} / \mathrm{m}^{3}\right)$ that can be present in the working environment (Goyer et al, 2006). The exhaust from the debinding oven must be treated in two steps to get rid of the toxic bi-product of the depolymerization of POM, which are nitrogen dioxide $\left(\mathrm{NO}_{2}\right)$ and formaldehyde $\left(\mathrm{CH}_{2} \mathrm{O}\right)$. First the exhaust is burned in a reducing atmosphere (no oxygen and rich in nitrogen) at a temperature of $600{ }^{\circ} \mathrm{C}$, transforming nitric dioxide into nitrogen gas $\left(\mathrm{N}_{2}\right)$. The second step consists of burning in an oxidizing atmosphere at $800{ }^{\circ} \mathrm{C}$ to transform formaldehyde into water and carbon dioxide (Torralba et al, 2011). If properly treated, the exhaust fumes coming out of the debinding oven does not represent a health hazard.

It is important to mention that binders based on POM usually have a backbone polymer which is not susceptible to catalytic debinding. Such backbone polymer helps retain strength and shape stability in the "brown part". However, sintering cannot begin in the presence of this backbone polymer and thus a thermal treatment between 200 and $600{ }^{\circ} \mathrm{C}$ is applied to the part prior to the start of the sintering process (Tandon, 2008). 


\subsection{Comparison between debinding processes}

The major differences, advantages and disadvantages between the three types of debinding techniques are summarized in Table 3.

\begin{tabular}{|c|c|c|c|}
\hline $\begin{array}{l}\text { Debinding } \\
\text { Technique }\end{array}$ & Key Features & Advantages & Disadvantages \\
\hline Thermal & $\begin{array}{l}\text { Slowly heat green part } \\
\text { to melting or } \\
\text { degradation } \\
\text { temperatures with a } \\
\text { continuous sweep gas } \\
\text { to remove binder. }\end{array}$ & $\begin{array}{l}\text { One-step process, no } \\
\text { need to handle product } \\
\text { between debinding and } \\
\text { sintering (unless wicking } \\
\text { is used). Low cost } \\
\text { installation. Applicable to } \\
\text { a wide range of binders. }\end{array}$ & $\begin{array}{l}\text { Soft binder allows warpage, } \\
\text { poor dimensional control } \\
\text { and relatively slow process } \\
\text { (up to } 60 \mathrm{~h} \text { ). If a wick is used } \\
\text { problems to separate part } \\
\text { from it. }\end{array}$ \\
\hline Solvent & $\begin{array}{l}\text { Green part is placed in } \\
\text { a solvent in gaseous or } \\
\text { liquid state to extract } \\
\text { binder via dissolution. }\end{array}$ & $\begin{array}{l}\text { Component remains rigid } \\
\text { without chemical } \\
\text { reactions. Lower } \\
\text { temperatures minimize } \\
\text { defects and distortions. } \\
\text { Faster than thermal } \\
\text { debinding (around } 6 \mathrm{~h} \text { ) }\end{array}$ & $\begin{array}{l}\text { Solvent hazard, chemical } \\
\text { handling and environmental } \\
\text { concern (unless water } \\
\text { soluble binder is used). } \\
\text { Expensive equipment if } \\
\text { using supercritical } \\
\text { extraction. Drying before } \\
\text { sintering required if using } \\
\text { liquid solvent. }\end{array}$ \\
\hline Catalytic & $\begin{array}{l}\text { Heat green part in } \\
\text { atmosphere } \\
\text { containing catalyst to } \\
\text { depolymerize binder } \\
\text { and sweep away } \\
\text { monomers. Binder } \\
\text { goes from solid to gas. }\end{array}$ & $\begin{array}{l}\text { Rapid process ( } 4 \text { to } 6 \mathrm{~h} \text { ) } \\
\text { that works well on thick } \\
\text { and thin sections with } \\
\text { excellent shape retention. }\end{array}$ & $\begin{array}{l}\text { Possible hazards with acid } \\
\text { catalysts and decomposition } \\
\text { products. Exhaust products } \\
\text { must be treated properly to } \\
\text { prevent health and } \\
\text { environmental hazards. }\end{array}$ \\
\hline
\end{tabular}

Table 3. Comparison between three major debinding techniques.

\section{Sintering}

The last step of the PIM process is sintering. Sintering is one of the oldest human technologies, originating in the prehistoric era with the firing of pottery. After the 1940s sintering has been studied fundamentally and scientifically leading to remarkable developments in sintering science. Nowadays, sintering can be used for the fabrication of all kinds of parts, including powder-metallurgical parts and bulk ceramic components (Kang, 2005).

Sintering is a thermal treatment that transforms metallic or ceramic powders into bulk materials with improved mechanical strength that in most cases have residual porosity. Sintering is performed at temperatures below the melting temperature of the major constituent in the metal or ceramic powder, generally within 70 to $90 \%$ of the melting point (Lame et al, 2003). The temperature inside the sintering furnace is high enough to start the recrystallization process of the metal or ceramic particles, but low enough so that the particles remain unmelted. At such temperatures, the particles recrystallize into each other causing them to fuse together (Boljanovic, 2010). 
During sintering, solid-state atomic diffusion takes place, followed by recrystallization and grain growth. When the temperature exceeds one half to two thirds of the melting temperature of the powder material, significant atomic diffusion occurs and some chemical changes may happen on the surface of the particles, such as the vaporization of chemically bounded water. As temperature keeps increasing, thermolysis occurs which is a process that burns out the organic components such as remaining binder, dispersant, etc. During sintering there is a great deal of particle movement and mass transport. It has been identified that there are at least six different mechanisms for mass transfer involved in sintering, which are surface diffusion, evaporation-condensation, grain boundary diffusion, lattice diffusion, viscous flow, and plastic flow. These mechanisms lead to growth of necks between particles and thus increase the strength of the consolidated powders. However some mechanisms also lead to shrinkage (more than 10\%) and densification. Surface diffusion is the mechanism that produces surface smoothing, particle joining and pore rounding, but not volume shrinkage. If the material has high vapor pressure, sublimation and vapor transport produce the same effects as surface diffusion. Diffusion along the grain boundaries and through the lattice produces both neck growth and volume shrinkage. Bulk viscous flow plays an important role in densification when a wetting liquid is present, while plastic deformation is important when a mechanical pressure is applied (Kang, 2007).

Fusing of the metallic particles during the sintering process has been observed using synchrotron microtomography as shown in the figures below for copper particles. It is clearly observed that during sintering the particles get closer to each other as interparticle necks grow and the porosity is reduced. From room temperature (Fig. 13A) to $1000^{\circ} \mathrm{C}$ (Fig. 13B) there is no significant shrinkage but the neck formation causes small displacements and rotations of the particles that lead to a different particle packing. As a result of this rearrangement, some pores decrease in size but others increase. After sintering for $120 \mathrm{~min}$ at $1050{ }^{\circ} \mathrm{C}$, the interparticle necks have grown up and it is harder to distinguish individual particles (Fig. 13C). Finally, (Fig. 13D) after the part was sintered for an additional $100 \mathrm{~min}$ and cooled down to room temperature, most pores have vanished but some large pores remain (Lame et al, 2003).

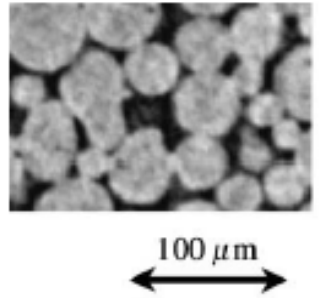

(A)

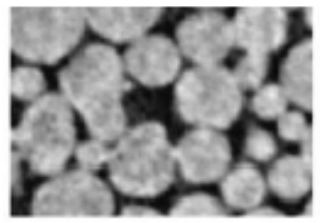

(B)

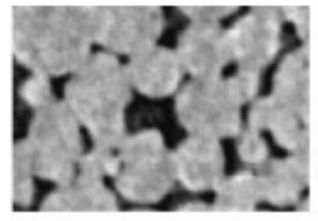

(C)

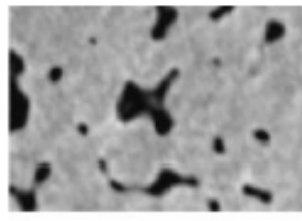

(D)

Fig. 13. Non-compacted copper particles at different stages of the sintering process, (A) at room temperature before sintering, (B) after heating to $1050{ }^{\circ} \mathrm{C}$ from room temperature in 45 min, (C) at $1050{ }^{\circ} \mathrm{C}$ after $120 \mathrm{~min}$ of sintering, and (D) after sintering for $220 \mathrm{~min}$ at $1050{ }^{\circ} \mathrm{C}$ and cooling to room temperature in $15 \mathrm{~min}$ (Lame et al, 2003).

Depending on the size of the part and the material used, the sintering time can vary. For small parts such as bushings, the average time varies from 1 to $1.5 \mathrm{~h}$. For average-size ferrous parts, the sintering time can be $3 \mathrm{~h}$. However tungsten parts can have a sintering time of up to $8 \mathrm{~h}$. In 
order to harden sintered parts, a controlled cooling rate must be carried out in a separate section of the sintering furnace. Cooling is done in a protective atmosphere in order to prevent oxidation of sintered parts. Dissociated ammonia and nitrogen-based atmospheres are commonly used, however vacuum atmospheres are also used for stainless steel and tungsten parts for example. The cooling rate is critical since the mechanical properties of the sintered parts is affected by the phase transformation of the material (Boljanovic, 2010).

\section{Conclusion - Closing remarks}

PIM is a powerful process for the manufacturing of parts with complex geometry. It combines the design benefits of thermoplastic injection molding and the efficiency of powder metallurgy. Due to its capability is expected that PIM will growth in importance. However the current state of the art does not allow for PIM to be widely used and therefore there is a need to optimize the process to increase its efficiency and productivity, as well as the quality of the final parts. For instance, there is still room for improving the performance of binders as to obtain excellent flowability in the molten state while having high mechanical properties in the solid state. Optimization can also be brought into the powder design as to obtain the most adequate particle size distribution and size ratios for multimodal powders. Also, it has been shown that using nanoparticles brings many benefits into the PIM process, but handling procedures of these materials and their processing to avoid agglomeration is still far from optimal. In summary, PIM technology still offers a broad field of opportunities for improvement through applied research.

\section{References}

Ahn, S., Park, S.J., Lee, S., Atre, S.V. \& German, R.M. (2009). Effect of powders and binders on material properties and molding parameters in iron and stainless steel powder injection molding process. Powder Technology, Vol.193, No.2, (July 2009), pp.162-169, ISSN 0032-5910.

Aggarwal, G., Smid, I., Park, S.J. \& German, R.M. (2007). Development of niobium powder injection molding. Part II: Debinding and sintering. International Journal of Refractory Metals \& Hard Materials, Vol.25, No.3, (May 2007), pp. 226-236, ISSN 0263-4368.

Arburg. (2009). Powder Injection Moulding (PIM) - Production of complex moulded parts from metal and ceramic. Arburg GmbH + Co KG, Lossburg, Germany, Available from: http://www.arburg.de/com/common/download/WEB_522785_en_GB.pdf

Auzene, D. \& Roberjot, S. (2011). Investigation into water soluble binder systems for powder injection moulding. Powder Injection Moulsding International, Vol.5, No. 1, (March 2011), pp.54-57, ISSN 1753-1497.

Boljanovic, V. (2010). Powder metallurgy. In Metal Shaping Processes: Casting and Molding, Particulate Processing, Deformation Processes, Metal Removal. Industrial Press Inc., ISBN 9780831 133801, New York, USA, pp. 75-106.

Chan, T.Y. \& Lin, S.L. (1995). Effects of stearic acid on the injection molding of alumina. Journal of the American Ceramic Society, Vol.78, No.10, (October 1995), pp. 2746-2752, ISSN 1551-2916.

Clemens, F. (2009). Thermoplastic extrusion for ceramic bodies. In Extrusion in CeramicsEngineering Materials and Processes, Handle, F. (Ed.), Springer-Verlag, , ISBN 9783540271000, Berlin, Germany, pp. 295-311. 
Chuankrerkkul, N., Messer, P.F. \& Davies, H.A. (2007). Powder injection moulding of cemented carbides: Feedstock preparation and injection moulding. Journal of Metals, Materials and Minerals, Vol.17, No.1 (May 2007), pp.53-57, ISSN 0857-6149.

Dos Santos, M.A., Neivock, M.P., Maliska, A.M., Klein, A.N. \& Muzart, J.L.R. (2004). Plasma debinding and pre-sintering of injected parts. Material Research, Vol.7, No.3, (July/September 2004), pp.505-511, ISSN 1516-1439.

Emri, I., \& von Bernstorff, B.S. (2006). The effect of molecular mass distribution on timedependent behavior of polyamides. Journal of Applied Mechanics, Vol.73, No.5, (September 2006), pp.752-757, ISSN 0021-8936.

Fu, G., Loh, N.H., Tor, S.B., Tay, B.Y., Murakoshi, Y. \& Maeda, R. (2005). Injection molding, debinding and sinterng of 316L stainless steel microstructures. Applied Physics A,Vol. 81, No.3, (May2005), pp.495-500, ISSN 0947-8396.

German, R.M. (1990). Powder Injection Moulding. Metals Powder Industries Federation, ISBN 0918404959, Princeton, New Jersey, USA.

German, R.M. (2008). PIM breaks the $\$ 1$ bn barrier. Metal Powder Report, Vol.63, No.3, (March 2008), pp.8-10, ISSN 0026-0657.

German, R.M. \& Bose, A. (1997). Injection Moulding of Metals and Ceramics. Metals Powder Industries Federation, ISBN 187895461X, Princeton, New Jersey, USA.

GIA. (2011). Metal and Ceramic Injection Molding. Global Industry Analysts, Inc., San Jose, USA.

Gonçalves, A.C. (2001). Metallic powder injection molding using low pressure. Journal of Materials Processing Technology, Vol.118, No.1-3, (December 2001) pp.193-198, ISSN 0924-0136.

Goyer, N., Bégin, D., Beaudry, C., Bouchard, M., Carrier, G., Lavoué, G., Noisel, N. \& Gérin, M. (2006). Prevention guide- Formaldehyde in the work place. Institute de reserche Robert-Sauvé en santé et en sécurité du travail (IRSST), Montreal, Canada. Accessed: August 28, 2011, Available from:

http:/ / www.irsst.qc.ca/media/documents/PubIRSST/RG-473.pdf, ISBN 9782896310692

Hartwig, T., Veltl, G., Petzoldt, F., Kunze, H., Scholl, R. \& Kieback, B. (1998). Powders for metal injection molding. Journal of European Ceramic Society, Vol.18, No. 9, (October 1998), pp.1211-1216, ISSN 0955-2219.

Hausnerová, B. (2011). Powder injection moulding- An alternative processing method for automotive items. In New Trends and Developments in Automotive System Engineering, Chiaberge M. (Ed.), InTech, ISBN 9789533075144, Rijeka, Croatia, pp.129-145.

Hausnerová, B., Saha, P. \& Kubat, J. (1999). Capillary flow of hard-metal carbide powder compunds. International Polymer Processing, Vol.14, No. 3, (March 1999), pp.254260, ISSN 0930-777X.

Kang, L. (2007). Ceramic Membranes for Separation and Reaction. John Wiley and Sons, ISBN 9780470014400, Chichester, England, 306 pages.

Kang, S.J. (2005). Sintering: Densification, Grain Growth \& Microstructure. Elsevier Butterworth-Heinemann, ISBN 9780750663864, Oxford, U.K. 265 pages.

Kankawa, Y. (1997). Effects of polymer decomposition behavior on thermal debinding process in metal injection molding. Materials and Manufacturing Processes, Vol.12, No. 4, (April 1997), pp.681-690, ISSN 1042-6914.

Krueger, D., Bloemacher, M. \& Weinand, D. (1993). Rapid catalytic debindng MIM feedstock, a new technology grows into a manufacturing process, In Advances in 
Powder Metallurgy and Particulate Materials, Metal Powder Industries Federation, Princeton, New Jersey, USA, Vol. 5. No.2, pp. 165-180, ISSN 1065-5824.

Krueger, D.C. (1996). Process for improving the debinding rate of ceramic and metal injection molded products. US Patent 5531958.

Krug, S., Evans, J.R.G. \& ter Matt, J.H.H. (2000). Residual stresses and cracking in large ceramic injection mouldings subjected to different solidification schedules. Journal of the European Ceramic Society, Vol.20, No.14-15, (December 2000), pp.2535-2541, ISSN 0955-2219.

Krug, S., Evans, J.R.G. \& ter Maat, J.H.H. (2001). Transient effects during catalytic binder removal in ceramic injection moulding. Journal of the European Ceramic Society, Vol.21, No.12, (October 2001), pp.2275-2283, ISSN 0955-2219.

Krug, S., Evans, J.R.G. \& ter Maat, J.H.H. (2002). Differential sintering in ceramic injection moulding: particle orientation effects. Journal of the European Ceramic Society, Vol.22, No. 2, (February 2002), pp.173-181, ISSN 0955-2219.

Kubyshkina, G., Zupančič, B., Stukelj, M., Grošelj, D., Marion, L. \& Emri, I. (2011). The influence of different sterilization techniques on the time-dependent behavior of polyamides. Journal of Biomaterials and Nanobitechnology (accepted for publication), ISSN 2158-7027.

Lame, O., Bellet, D., Di Michiel, M. \& Bouvard, D. (2003). In situ microtomography investigation of metal powder compacts during sintering. Nuclear Instruments and Methods in Physics Research B, Vol.200, (January 2003), pp.287-294, ISSN 0168-583X.

Liu, Z.Y., Loh, N.H., Tor, S.B. \& Khor, K.A. (2003). Characterization of powder injection molding feedstock. Materials Characterization, Vol.49, No. 4, (November 2002), pp.313-320, ISSN 1044-5803.

Mathew, B.A. \& Mastromatteo, R. (2003). MIM Focus- Metal injection moulding for automotive applications. Metal Powder Report, Vol.58, No.3, (March 2002), pp.32-35, ISSN 0026-0657.

Merz, L., Rath, S., Piotter, V., Ruprecht, R., Ritzhaupt-Kleissl, J. \& Haussel, J. (2002). Feedstock development for micro powder injection molding. Microsystem Technologies, Vol.8, No. 2-3, (March 2002), pp.129-132, ISSN 0946-7076.

Neikov, O.D., Naboychenko, S., Gopienko, V.G. \& Frishberg, I.V. (2009). Handbook of NonFerrous Metal Powders: Technologies and applications, Elsevier, ISBN 9781856174220, Amsterdam, The Netherlands, 634 pages.

Oliveira, R.V.B., Soldi, V., Fredel, M.C. \& Pires, A.T.N. (2005). Ceramic injection molding: influence of specimen dimensions and temperature on solven debinding kinetics. Journal of Materials Processing Technology, Vol.160, No.2, (March 2005), pp.213-220, ISSN 0924-0136.

Pioter, V., Bauer, W., Benzler, T. \& Emde, A. (2001). Injection molding of components for microsystems. Microsystem Technologies, Vol.7, No. 3, (March 2001), pp.99-102, ISSN 0946-7076.

Quinard, C., Barriere, T., Gelin, J.C. (2009). Development and property identification of 316L stainless steel feedstock for PIM and $\mu$ PIM. Powder Technology, Vol.190, No.1-2, (March 2009), pp.123-128, ISSN 0032-5910.

Rahaman, M.N. (2003). Ceramic processing and sintering, Marcel Dekker, ISBN 9780824709884, Basel, Switzerland, pp. 49-122.

Rosato, D.V. \& Rosato, D.V. (1996). Specialized injection molding process. In Injection Molding Handbook, 2nd edition. Chapman \& Hall GmbH, ISBN 9780792386193, Weinheim, Germany, pp. 1005-1058. 
Rothon, R.N. (2003). Particulate-Filled Polymer Composites, 2nd edition. Smithers Rapra Technology Limited, ISBN 9781859573822, Shropshire, United Kingdom, pp. 29-33.

Ruprecht, R., Gietzelt, T., Müller, K., Piotter, V. \& Haußelt, J. (2002). Injection molding of microstructured components from plastics, metals and ceramics. Microsystem Technologies, Vol.8, No.4-5, (May 2002), pp.351-358, ISSN 0946-7076.

Schrader, G.F., Elshennawy, A.K. \& Doyle, L.E. (2000). Powder Metalurgy. In Manufacturing Process and Materials. Society of Manufacturing Engineers, ISBN 0872635171, Dearborn, Michigan, USA, pp. 199-209.

Shearwood, C., Fu, Y.Q., Yu, L. \& Khor, K.A. (2005). Spark plasma sintering of TiNi nanopowder. Scripta Materialia, Vol.52, No.6, (March 2005), pp.455-460, ISSN 1359-6462.

Somasundram, I.M., Cendrowicz, A., Wilson, D.I. \& Johns, M.L. (2008). Phenomenological study and modelling of wick debinding. Chemical Engineering Science, Vol.63, No.14, (July 2008), pp.3802-3809, ISSN 0009-2509.

Stevenson, J.F. (2009). Powder Metal Injection Molding. In Injection Molding - Technology and Fundamentals, Kamal, M.R., Isayev, A.I., \& Liu, S.J. (Ed), Cal Hanser Verlag, ISBN 978156904343, Munich, Germany, pp. 309-340.

Stringari, G., Zupančič, B., Kubyshkina, G., von Bernstorff, B. \& Emri, I. (2011). Timedependant properties of bimodal POM - Application in powder injection molding. Powder Technology, Vol.208, No. 3, (April 2011), pp.590-595, ISSN 0032-5910.

Tandon, R. (2008). Metal injection moulding. In Encyclopedia of Materials: Science and Technology, Buschow, K.H.J., Cahn, R.W., Flemings, M.C., Ilscher, B., Kramer, E.J., Mahajan, S. \& Veyssiere, P. (Ed.), Elsevier Science Ltd, ISBN 9780080431529, Amsterdam, The Netherlands, pp.5439-5442.

Tay, B.Y., Loh, N.H., Tor, S.B., Ng, F.L., Fu, G. \& Lu, X.H. (2009). Characterisation of micro gears produced by micro powder injection moulding. Powder Technology, Vol.188, No. 3, (January 2009), pp.179-182, ISSN 0032-5910.

Thomas-Vielma, P., Cervera, A., Levenfeld, B. \& Várez, A. (2008). Production of alumina parts by powder injection molding with a binder system based on high density polyethylene. Journal of the European Ceramic Society,Vol.28, No. 4, (October 2007), pp.763-771, ISSN 0955-2219.

Thornagel, M. (2010). PIM 2010- Simulating flow can help avoid mould mistakes. Metal Powder Report, Vol.65, No.3, (March-April 2010), pp. 26-29, ISSN 0026-0657.

Torralba, J.M., Hidalgo, J. \& Jimenez-Morales, A. (2011). Powder injection moulding: Processing of small parts of complex shape, Proceedings of ICITEMPT 2011 8th International Conference on Industrial Tools and Material Processing Technologies, pp. 53-58, ISBN 9789616692021, Ljubljana, Slovenia, October 2-5, 2011.

Tseng, J.W. \& Hsu, C.K. (1999). Cracking defect and porosity evolution during thermal debinding in ceramic injection moldings. Ceramics International, Vol.25, No. 5, (July 1999), pp.461-466, ISSN 0272-8842.

Yang, W.W., Yang, K.Y. \& Hon, M.H. (2002). Effects of PEG molecular weights on rheological behavior of alumina injection molding feedstocks. Materials Chemistry and Physics, Vol.78, No. 2, (February 2002), pp.416-424, ISSN 0254-0584.

Zauner, R. (2006). Micro powder injection moulding. Microelectronics Engineering, Vol.83, No. 4-9, (April - September 2006), pp.1442-1444, ISSN 0167-9317. 


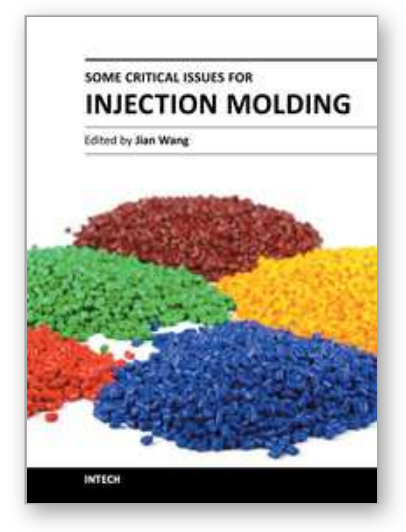

\author{
Some Critical Issues for Injection Molding \\ Edited by Dr. Jian Wang
}

ISBN 978-953-51-0297-7

Hard cover, 270 pages

Publisher InTech

Published online 23, March, 2012

Published in print edition March, 2012

This book is composed of different chapters which are related to the subject of injection molding and written by leading international academic experts in the field. It contains introduction on polymer PVT measurements and two main application areas of polymer PVT data in injection molding, optimization for injection molding process, Powder Injection Molding which comprises Ceramic Injection Molding and Metal Injection Molding, ans some special techniques or applications in injection molding. It provides some clear presentation of injection molding process and equipment to direct people in plastics manufacturing to solve problems and avoid costly errors. With useful, fundamental information for knowing and optimizing the injection molding operation, the readers could gain some working knowledge of the injection molding.

\title{
How to reference
}

In order to correctly reference this scholarly work, feel free to copy and paste the following:

Joamín González-Gutiérrez, Gustavo Beulke Stringari and Igor Emri (2012). Powder Injection Molding of Metal and Ceramic Parts, Some Critical Issues for Injection Molding, Dr. Jian Wang (Ed.), ISBN: 978-953-51-0297-7, InTech, Available from: http://www.intechopen.com/books/some-critical-issues-for-injection-molding/powderinjection-molding-of-metal-and-ceramic-parts-

\section{INTECH}

open science | open minds

\section{InTech Europe}

University Campus STeP Ri

Slavka Krautzeka 83/A

51000 Rijeka, Croatia

Phone: +385 (51) 770447

Fax: +385 (51) 686166

www.intechopen.com

\section{InTech China}

Unit 405, Office Block, Hotel Equatorial Shanghai

No.65, Yan An Road (West), Shanghai, 200040, China

中国上海市延安西路65号上海国际贵都大饭店办公楼405单元

Phone: +86-21-62489820

Fax: +86-21-62489821 
(C) 2012 The Author(s). Licensee IntechOpen. This is an open access article distributed under the terms of the Creative Commons Attribution 3.0 License, which permits unrestricted use, distribution, and reproduction in any medium, provided the original work is properly cited. 